\title{
THE ANATOMY OF THE SACRO-UTERINE LIGAMENTS
}

\author{
FRANK E. BLAISDELL, SR. \\ From the Laboratory of Surgical Pathology of the Medical School of Stanford \\ University \\ TWENTY-TWO FIGURES \\ CONTENTS
}

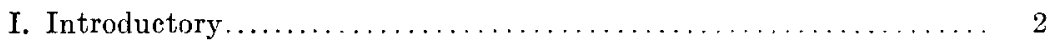

II. Methods of study and material.......................... 2

III. Brief review of the literature......................... 3

a. Chronological............................. 3

b. Descriptive and topographical.................... 4

IV. Explanatory remarks................................ 6

V. Comparative series............................... 6

1. Guinea pig (Cavia cabayia)....................... 8

2. Belgian hare (Lepus europaeus) ................... 9

3. Cat (Felis domesticus) ........................... 11

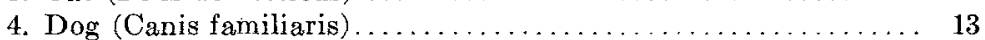

5. General considerations.......................... 14

VI. Primate series.................................. 15

1. Monkey (Macacus) ............................. 15

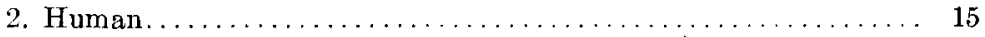

a. Examination of the structures in a recent post-mortem state................................... 15

b. Histological observations. Fixed material............ 19

1. Adult 35 years old ....................... 19

2. Child 10 years old .......................... 20

3. Infant 40 days old ......................... 21

4. Adult 65 years old ........................... 24

5. Adult 83 years old......................... 26

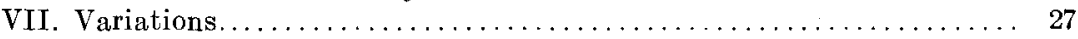

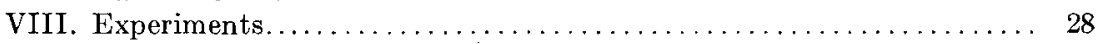

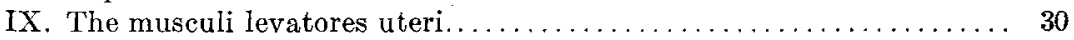

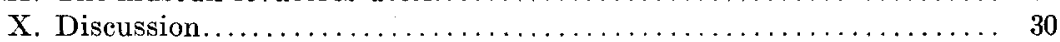

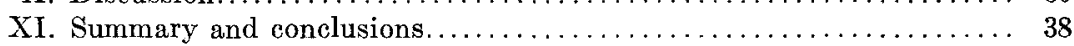

XII. Literature cited....................................... 41

THE ANATOMICAL RECORD, VOL. 12 , No. 1 FEBRDARY 1917 


\section{INTRODUCTORY}

A great deal has been written upon the anatomy of the pelvic floor and the mechanical supports of the pelvic viscera. While all of the contributors have more or less advanced our knowledge of the anatomy of the pelvis, all have failed to completely elucidate the anatomical and physiological importance of the fibro-elastic tissue that forms a more or less dense mesh-work, filling up the interval between the peritoneum above; the pelvic diaphragm covered by its facial sheath below; the obturator fascia and periosteum of the innominate bone laterally; the bladder, vagina, and uterus with their fibrous investment medially; and finally, the fascia over the sacral promontory, sheath of the sacral plexus, and fibrous tunic of the rectum, posteriorly. Cameron and Moritz have made the nearest approach to the proper solution of the question, but they failed in not subjecting the 'compact mass' filling up the interval between the peritoneum and pelvic floor as above limited to the proper anatomical analysis.

The primary object of the present investigation is the study of the so-called sacro-uterine ligaments; to determine what they really are and to establish their relation to the transverse ligaments of the uterine neck, recto-uterine muscles and rectouterine folds.

\section{METHODS OF STUDY AND MATERIAL}

From a survey of the work which has been done, it is evident that a comparative and a more comprehensive study is absolutely necessary for the proper solution of the problem. In accordance with that view, cadavers that had been embalmed in the usual manner for dissection, and others preserved with 10 to 40 per cent solutions of formaldehyde, and fresh material in and from the autopsy room, were used. Recent or unfixed material has the advantage of being perfectly flexible, permitting of experimental procedures not possible on the firm and inelastic material of the dissecting room. Finally, a careful study of frozen sections revealed some most interesting points. 
The human material included fetuses, the new born, and cadavers of the following ages: 40 days, 10, 24, 35, 65, and 83 years. The animals most readily available were the guinea pig (Cavia cabayia), Belgian hare (Lepus europaeus), cat (Felix domestica), dog (Canis familiaris), and monkey (Macacus). In the whole series the parametrium containing the so-called ligaments and folds were cut in serial sections and subjected to a careful examination. Experimental observations on the pelvic organs were made on the animals while under an anesthetic.

Since the appearance of a preliminary report of this paper in June, 1913, there has been published an interesting paper by Moritz ('14), in which the author considers the distribution and significance of the parametrium. His method has been to obtain the pelvic contents as soon after death as possible, by having them removed right down to the bone and the pelvic floor cut away with them. The specimens were then fixed in 10 per cent solution of commercial formalin. Not 'dissected,' in the ordinary acceptation of the term, but sections were cut in varying planes and directions.

\section{BRIEF REVIEW OF THE LITERATURE}

\section{a. Chronological}

The more important contributors are the following:

Kocks, (1) ('80),

Hart, (2) ('80),

Mackenrodt, (3) ('95),

Holl, (4) ('97),

Harman, (5) ('98),

Thompson, (6) ('00-'06),

Deaver, (7) ('03),

Montgomery, (8) ('03),

Stony, (9) ('04),

Kocks (1) described the cardinal ligaments. Mackenrodt (3) defined the ligamentum transversale colli. Deaver (7) states that the false posterior or recto-uterine ligaments are composed of two peritoneal layers which pass backward from the posterior surface of the uterus and vagina to the upper portion of the rectum, forming the lateral boundaries of the pouch of Douglas; external to each are found the true or muscular utero-sacral ligaments, which are flat muscular bands that extend from the uterus at the level of the internal os, to the sides of the sacrum, passing beneath the layers of the recto-uterine ligaments. 
Montgomery (8) says that the utero-sacral ligaments, while consisting of folds of peritoneum, also contain muscle fibers, which are derived from the superior muscular layer of the uterus.

Paterson (11) considered the suspensory ligaments. Ovenden (12) reviews Mackenrodt's work and states that the ligamentum transversale colli is worthy of being recognized as a distinct ligament, and that the utero-sacral ligament blends with the former near its insertion into the uterus.

Cameron (13) considers the utero-sacral ligaments as a part of the general perivascular mass.

Moritz (17) in criticizing Dr. Ovenden's views states: "I hope to demonstrate that the sketch she published of the insertion of the ligament (transverse of the neck) shows clearly that the so-called ligament is simply a portion of the parametrium containing the uterine artery, artificially separated from the surrounding mass." $\mathrm{He}$ agrees that the parametrium constituting the ligamentum transversum colli is of great importance physiologically, in that they fix the cervix and form the most fixed point of the uterus. In a brief summary he states that: "the whole structure is nothing but an inseparable continuation of parametrium which surrounds and fixes the cervix." He considers the utero-sacral ligaments as small folds of peritoneum, and contain nerves, perineural connective tissue and smooth muscle; they carry the nervi erigentes, pushing their way through the mesodermal tissue from their points of emergence from the anterior sacral foramen.

\section{b. Descriptive and topographical}

The descriptive and topographical statements by Cunningham (19) of the connections of the uterus and its relations to the peritoneum laterally and posteriorly may be taken as the consensus of opinion among anatomists. The deep pouch between the uterus and vagina in front and the rectum behind is called the pouch of Douglas (excavatio recto-uterina) and its entrance is bounded on each side by a crescentic peritoneal fold, which passes from the posterior surface of the cervix uteri to the posterior wall of the pelvis, and ends near the side of the rectum. These crescentic folds are called the recto-uterine folds (plicae recto-uterinae), and each contains between its layers a considerable amount of fibrous and smooth muscular tissue. Some of these fibers, which are continuous with the uterine wall, pass backward to reach the rectum and constitute the recto-uterine muscle (ligamentum sacro-uterinum). In many cases the recto-uterine folds become continuous with one another across the middle line behind the cervix uteri, and form a transverse ridge termed the torus uterinus.

A comparison of Morris (20), Piersol (21), and Gray (22) with Cunningham (19) and others, inevitably leaves the student in doubt as to what really constitutes a sacro-uterine ligament and its relation not only to the plica recto-uterina but the musculus recto-uterinus as well. 
Morris (20) calls the posterior peritoneal folds of the uterus, 'the recto-uterine ligaments,' and states that they become continuous with the peritoneal investment of the second part of the rectum, and that between their layers lie the utero-sacral ligaments, the latter being flat fibro-muscular bands, extending from the highest part of the cervix uteri, where they are more or less continuous with the uterine fibers in the recto-uterine peritoneal folds, to the sides of the sacrum

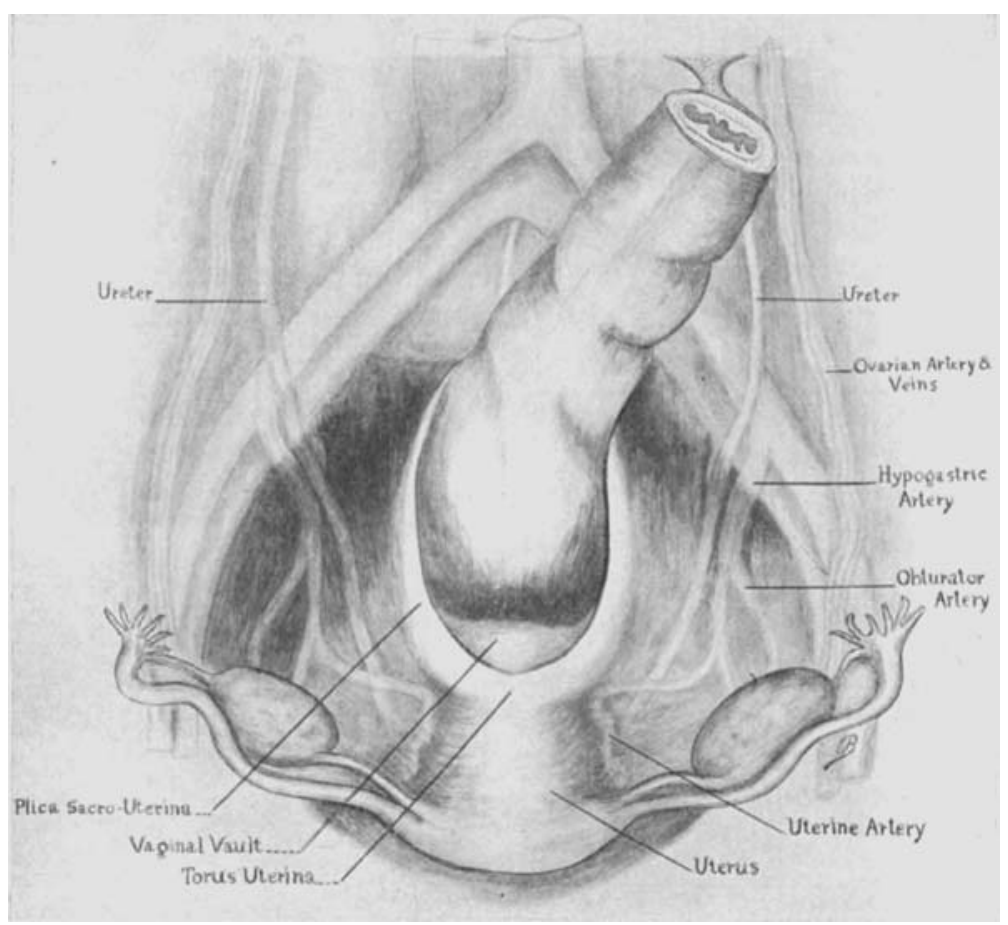

Fig. 1 Semi-diagrammatic drawing of female pelvic viscera viewed from above, uterus and adnexa being drawn forward and vessels projected against peritoneum.

opposite the lower border of the sacro-iliac articulation. They run one on each side of the rectum near the junction of the first and second parts. Their muscle fibers (the recto-uterine muscles) become continuous with those of the rectum posteriorly and more anteriorly they lie in the recto-uterine peritoneal folds, which form the lateral boundaries of the pouch of Douglas.

Piersol (21) states that between the layers of the folds (plicaerecto-uterinae) robust bundles of fibrous and smooth muscular tissue 
FRANK E. BLAISDELL, SR.

extend from the uterus to be inserted partly into the rectum, these constituting the utero-rectal muscle, and partly into the front of the sacrum as the utero-sacral ligament.

Gray (22) says that the sacro-uterine ligaments (plicae-rectouterinae) are contained in the peritoneal folds of Douglas. They pass from the second and third bones of the sacrum, downward and forward on the lateral aspects of the rectum to be attached one on each side of the uterus at the junction of the supra-vaginal cervix and the body. They contain fibrous tissue and unstriated muscle fibers. Muscular fibers from the uterine wall to the rectal wall constitute the recto-uterine muscle. This muscle is part of the sacro-uterine ligaments.

\section{EXPLANATORY REMARKS}

The terms cardinal ligament, ligamentum transversale colli uterini and suspensory ligament are synonymous. The parametrium includes all of the fibro-elastic tissue lying lateral to the uterus; the paravaginal tissue that which lies opposite the vaginal vault; while the term paraplical will likewise signify the tissue lateral to the recto-uterine folds, or more specifically that lying lateral to the recto-uterine fossa and fibrous tunic of the rectum. It fills the subperitoneal cavity as defined by Moritz.

The sacro-uterine and recto-uterine folds are the same structurally, the only difference being the manner of termination, which makes it necessary from a physiological standpoint to speak of them separately.

The term fibro-elastic will be used instead of Cameron's (13) term perivascular tissue, because the term perivascular defines only a part of the parametrial supporting tissue, and its function is not primarily to support blood vessels as will be explained later.

\section{COMPARATIVE SERIES}

In animals, which habitually assume the horizontal position in locomotion, there is to be found a simpler and less condensed condition of the uterus as regards bulk than in those animals which assume the erect position. Such animals possess either two uteri or a uterus bicornis. The uteri are therefore comparatively less bulky and the weight is distributed along a more extensive peritoneal attachment. Such attachment usually ex- 
tends as far cephalad as the caudal pole of the kidneys. At all times, except during short periods of time when other than the horizontal position is assumed, the weight of the uterus, distended bladder and rectum, cause these organs to fall ventrad in the hypogastric region of the abdominal cavity. The uterus in a state of physiological rest is relatively light and consequently there is less need of true or fibrous ligaments, such as are present in the higher Primates, where the uterus is more con-

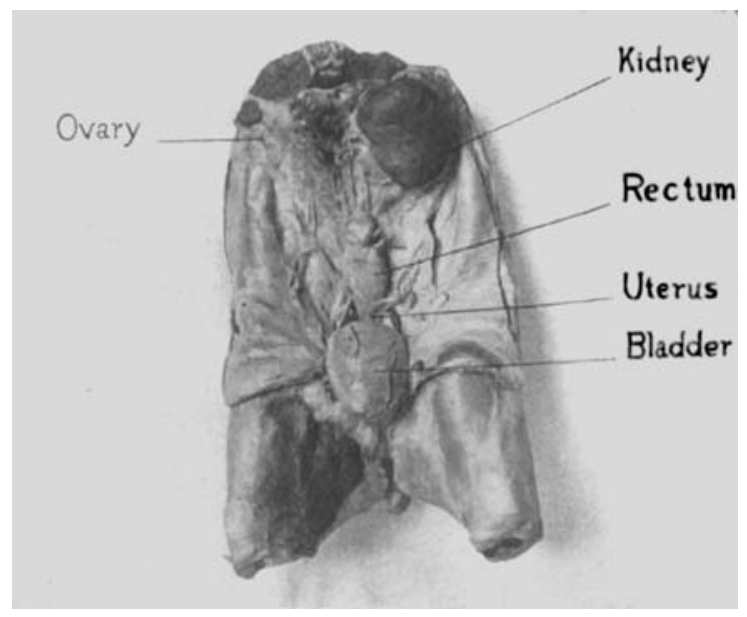

Fig. 2 Photograph showing relations of rectum, bladder and extensive peritoneal attachment of uterus in an animal which assumes the horizontal position in locomotion. Dog (Canis familiaris).

centrated in bulk and weight, and the erect position is assumed habitually, except during limited periods.

Therefore, in animals possessing a uterus bicornis, the peritoneal reflections are sufficient with a very meager amount of parametrial tissue to maintain the normal position of the organ. In the small series of animals examined during the preparation of this paper, one very important and significant fact was determined, and that is, that there were always bundles of smooth muscle fibers present in the peritoneal folds passing dorsad from the vagina to the rectum. Laterally, in the parametrial and paravaginal tissue, such bundles were practically 
absent and the fibro-elastic bundles were reduced to a minimum. It is therefore logical from an evolutionary standpoint to conclude that the presence of the recto-uterine muscle in these folds appears at an early date in the vertebrate series, and that they possess a phylogenetic significance.

\section{GUINEA PIG}

In the guinea pig, two distinct peritoneal folds pass dorsally from the sides of the vagina to the sides of the rectum. They

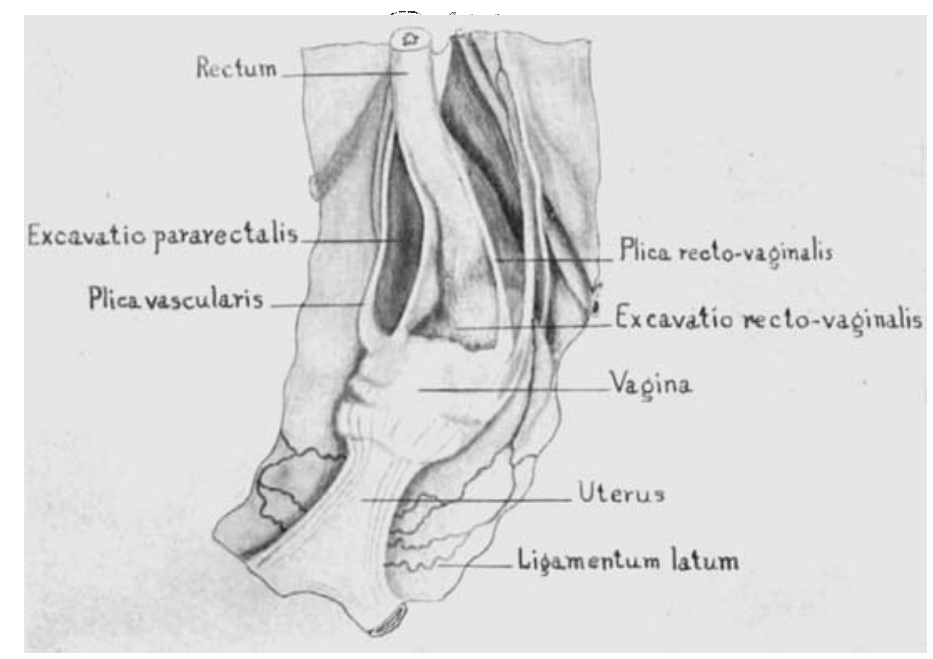

Fig. 3 Drawing showing rectum, vagina, uterus, recto-vaginal pouch and recto-vaginal folds in guinea pig (Cavia cabayia).

are therefore recto-vaginal folds, and must be termed the lateral folds to distinguish them from the median recto-vaginal reflection of peritoneum at the bottom of the recto-vaginal fossa. Lateral to the rectum and recto-vaginal fold is the pararectal fossa, which is in turn bounded laterally by a peritoneal fold conveying utero-vaginal blood vessels. The lateral rectovaginal folds and broad ligaments of the uterus are extremely thin and more or less transparent to translucent. By means of serial microscopical sections bundles of smooth muscle fibers 
have been traced from the uterus toward the rectum, in the recto-vaginal folds. These delicate muscular fasciculi are continuous with the noticeable longitudinal fibers on the dorsolateral facies of the uterus. It is important to note that the stratum fibrosum of the peritoneum shows marked thickening. The few muscular fasciculi that do reach the sides of the rectum may be traced along its lateral wall to be inserted into its fibrous sheath, or continuing dorsally, become lost in the mesorectum. Many of the fasciculi diminish in size as they pass through the folds, their fibers apparently becoming inserted into the peritoneum, but their actual termination has not been observed. Between the two peritoneal layers of the rectovaginal folds there is a small amount of extremely fine areolar tissue with a few fibro-elastic filaments. In the parametrial and paravaginal tissue there is a very meager amount of fibro-elastic elements. The cephalic extremity of the vagina is freely movable and lies between the bases of the broad ligaments. The recto-vaginal folds varied quite a good deal in size and symmetry in the different guinea pigs examined.

\section{BELGIAN HARE}

Distinct recto-vaginal folds are present. These and the broad ligaments are thin and more or less transparent, containing a varying amount of adipose tissue. Visible fibers are very sparse in the parametrial and paravaginal tissue. The free margins of the recto-vaginal folds are slightly thickened and opaque, as in the guinea pig. This opacity is due to temporary aggregation of the muscular fasciculi. The stratum fibrosum of the peritoneum constituting the folds, shows distinct thickening and at its deep surface passes insensibly into the extremely delicate areolar tissue between the layers, where also a few fibro-elastic bundles are found. In the parametrial and paravaginal tissue, there is a varying paucity of fibro-elastic bundles, but no fibers that could be taken to constitute potential ligaments, or noticeable aggregations of fibers to constitute true ligaments are present (fig. 5). The fasciculi of the recto-uterine muscle vary 


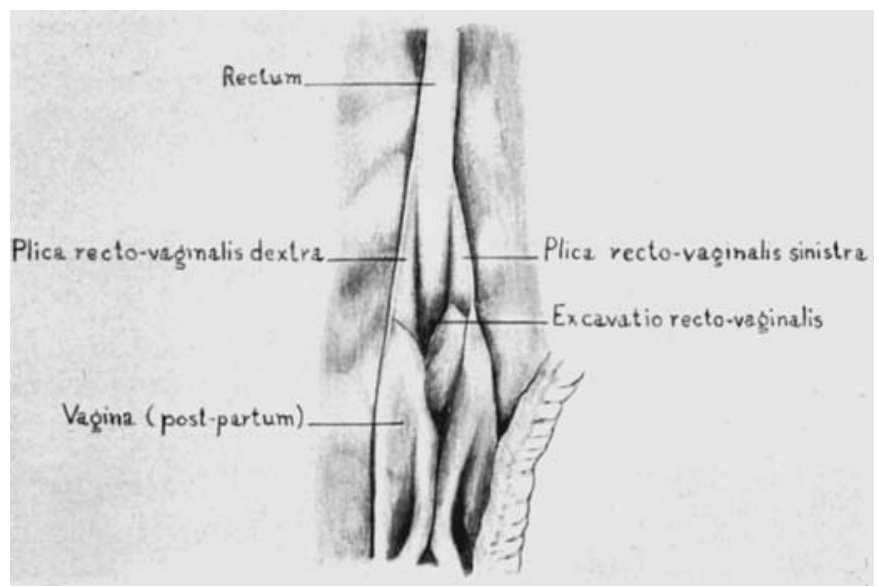

Fig. 4 Drawing showing rectum, vagina (post-partum) and recto-raginal folds in Belgian hare (Lepus europeaus).

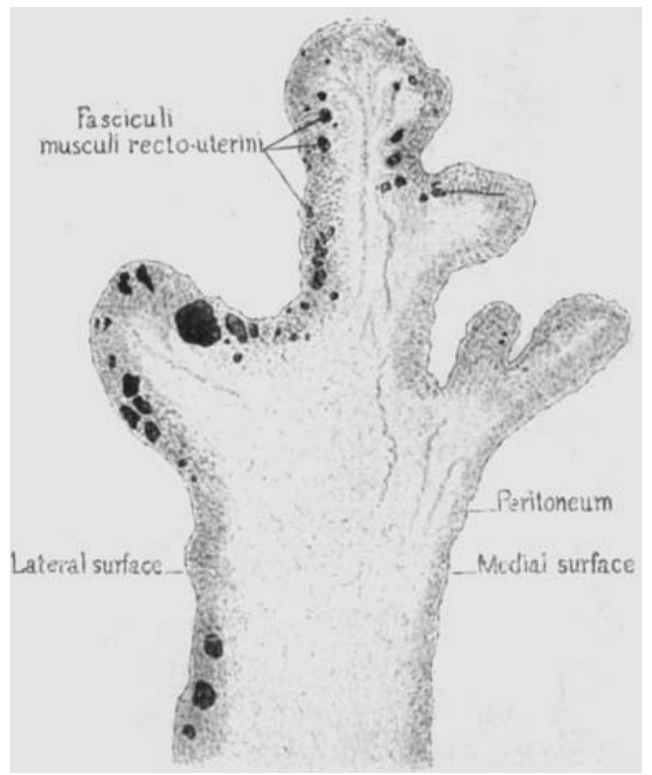

Fig. 5 Transverse section of a lateral recto-vaginal fold at middle third, showing distribution of fasciculi of reeto-uterine musele. Belgian hare. $\times 62$ Reduced to one-third. 
greatly in size and are distributed chiefly in the apical and lateral peritoneal layers of each fold. Many of the fasciculi appear to be almost submesothelial, others which are in the minority appear to be on the inner border-line of the stratum fibrosum, the majority however are in the more central parts of that layer. The muscular fasciculi are abundant in the vaginal extremity of the recto-vaginal fold, but become greatly diminished or absent in the rectal extremity of the same. A large percentage of the fasciculi therefore terminate in the fold probably by insertion into the more superficial part of the stratum fibrosum. Their actual termination has not been observed.

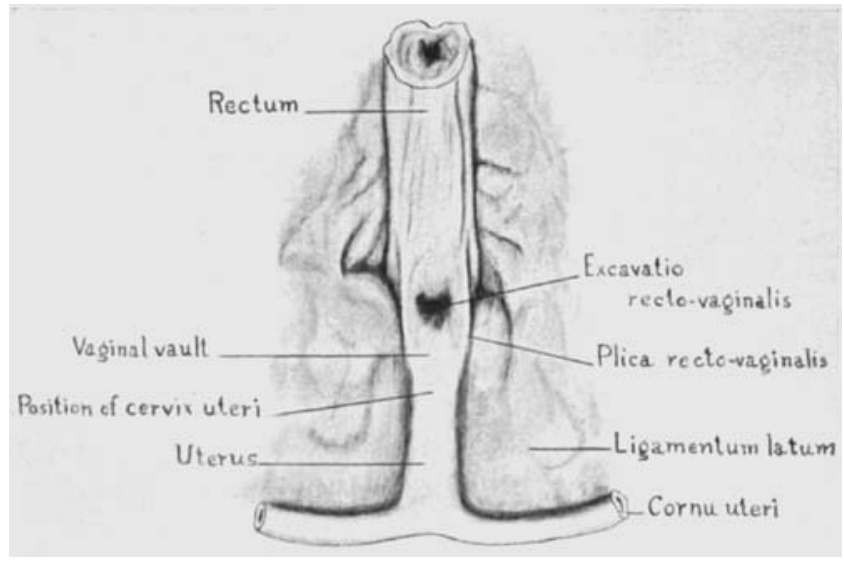

Fig. 6 Rectum, vagina and uterus of cat (Felis domestica), showing rectovaginal folds.

3. $\mathrm{CAT}$

The recto-vaginal folds are thicker and relatively smaller than in the hare, and pass more noticeably upon the ventral surface of the rectum; they are transparent as are also the broad ligaments. The recto-uterine muscles form distinet bands and attain the sides of the rectum; they are fusiform in transverse section and each carries its own blood-vessels. The stratum fibrosum of the peritoneum is distinctly thickened and contains the muscular fasciculi. The fasciculi are mast abundant and 
largest in the vaginal extremity of each fold, but many reach the side of the rectum and continue upon the same for a varying distance. They are not all in the prominent part of the fold on the rectum, for as the peritoneum spreads out the fasciculi necessarily go with it. The recto-vaginal folds vary in prominence and the distance to which they extend cephalad on the rectum depends on the degree of distention of the latter. It has

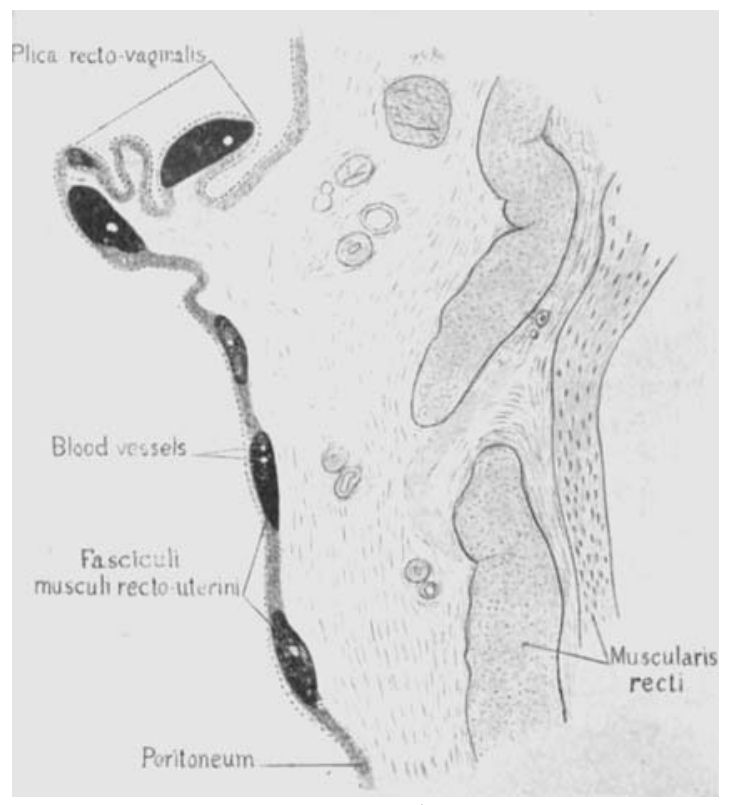

Fig. 7 Semi-diagrammatic drawing of lateral wall of rectum of cat, showing peritoneum and fasciculi of recto-uterine muscle, recto-vaginal folds and muscularis recti (Transverse section). $\times 175$. Reduced to one-third.

been observed that the peritoneum is anchored to the rectum by fibrous trabeculae which arise in the intermuscular fibrous tissue of the muscularis, which by passing outward, through intervals in the longitudinal layer become inserted into the stratum fibrosum.

Figure 8 shows the details of a muscular fasciculus, and its more or less centrally located blood vessel. In the majority of cases the vessels are intra-fascicular, but they vary in position to the periphery and may be supra-fascicular. 


\section{DOG}

In the dog, the anatomical relations between the pelvic viscera differ considerably from those in the series described above. The vagina during the inter-estral period is rather firmly fixed at its cephalic extremity. The bladder has a short but distinct neck, the peritoneum being reflected from the cervix vesicae upon the anterior vaginal wall before attaining the uterus. In the individuals examined small single or double recto-vaginal folds passed from the utero-vaginal junction to the rectum. The

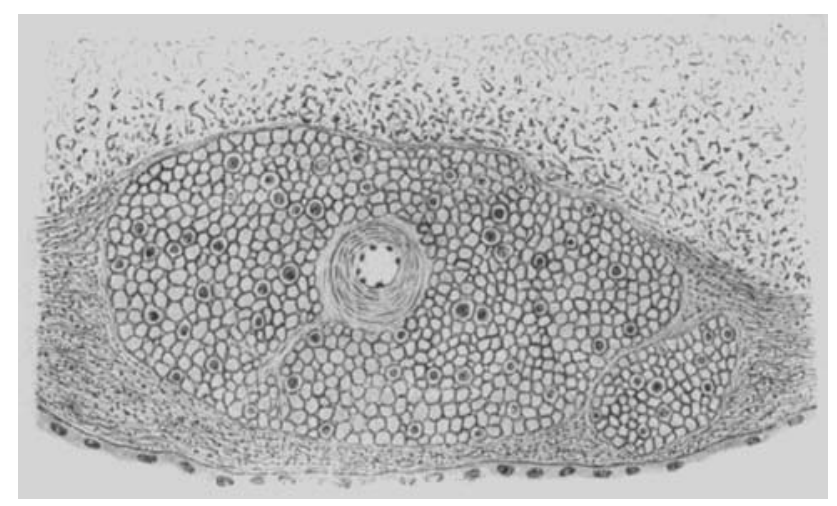

Fig. 8 Detailed camera lucida drawing of a fasciculus of recto-uterine muscle with its blood vessel, showing relation to peritoneum (Transverse section). Cat. $\times 235$. Reduced one-half.

ligaments of the bladder and uterus are thin, transparent and contain a varying amount of adipose tissue. The bladder possesses well developed dorso-lateral ligaments which suspend it from the dorsal pelvic wall. The uterus is held in close relation to the ventral surface of the rectum, by its relatively large broad ligaments which pass from the sides of the cervix and cornua, each crossing the dorso-lateral ligament of the bladder of its own side. The recto-uterine muscles pass nearly directly between the two organs, and in the small single or bilateral rectovaginal folds; or when one or both are absent by way of the peritoneum at the bottom of the recto-vaginal fossa. There is a broad recto-uterine space. Between the folds of the broad liga- 
ments and in the parametrium there is relatively a little more fibro-elastic tissue, but no aggregations which might be construed as constituting true or potential ligaments.

\section{GENERAL CONSIDERATIONS}

From the study of the above comparative series the following facts are to be noted. Distinct recto-vaginal folds pass from the dorsal wall and cephalic extremity of the vagina to the rectum, the former being more or less free and movable; that these

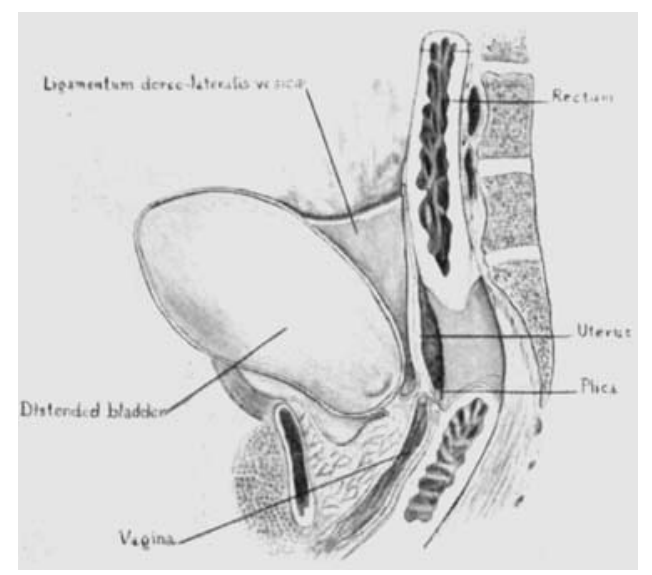

Fig. 9 Drawing of sagittal section of pelvis of a bitch showing relations of viscera and peritoneal folds.

recto-vaginal folds vary in size, and that they can be increased by traction on the uterus or more so by traction on both uterus and rectum. The stratum fibrosum of the peritoneum has in all cases undergone thickening or hypertrophy, and the fasciculi of the recto-uterine muscle are contained in it. The fasciculi of the latter are most abundant at the vaginal extremity of the fold and diminish in size and number as the rectum is approached, in some cases not reaching it. Some of the fibers of the muscular fasciculi are apparently inserted into the stratum fibrosum of the peritoneum, fewer of the bundles possibly being inserted into the fibrous tunic of the rectum or lost in the mesorectum. 
The fibro-elastic tissue constituting the parametrial, paravaginal and paraplical tissue is very scanty in amount and does not form aggregations to constitute so-called true ligaments, nor in sufficient quantity to form potential ligaments. The body of the vagina is more firmly attached than the cephalic extremity.

\section{PRIMATE SERIES}

\section{MONKEY (MACACUS)}

In the monkey, the uterus is undivided and the anatomical conditions are similar to those in the human female. The weight of the uterus is localized and therefore calls for stronger mechanical support. There is marked increase in the amount of the parametrial, paravaginal and paraplical fibro-elastic tissue, which can be recognized as constituting potential ligamentous aggregations. The specimens examined had unfortunately been embalmed in the usual way, but nevertheless the material demonstrated that the structure and relations were similar to those in the human female. Recto-uterine or sacro-uterine folds were absent, although potentially present. A short plica was present on each side at the utero-vaginal junction. These folds are not always present in woman, but can always be demonstrated as being potentially present, for traction forward on the uterus brings them into prominence. The thickened peritoneum with the recto-uterine muscles are always present.

The histological examination of the material from the monkey was not satisfactory as to details, on account of the amount of cytolysis and softening of the tissues generally, but everything indicated similar structural conditions as in woman.

\section{HUMAN}

For the purpose of establishing a point of departure, the pelvic structures in a state of full maturity or development in woman, will first be taken up, followed by those before maturity and, lastly, those in the stage of senility. 
a. Examination of the structures in a recent post mortem state

The careful dissection of the pelvic viscera of a woman 35 years old gave the following results: The recto-uterine folds were moderate in prominence and diminished gradually, to become lost in the general plane of the peritoneum without attaining the posterior pelvic wall. The rectum was median in position and without a mesorectum opposite the third sacral vertebra.

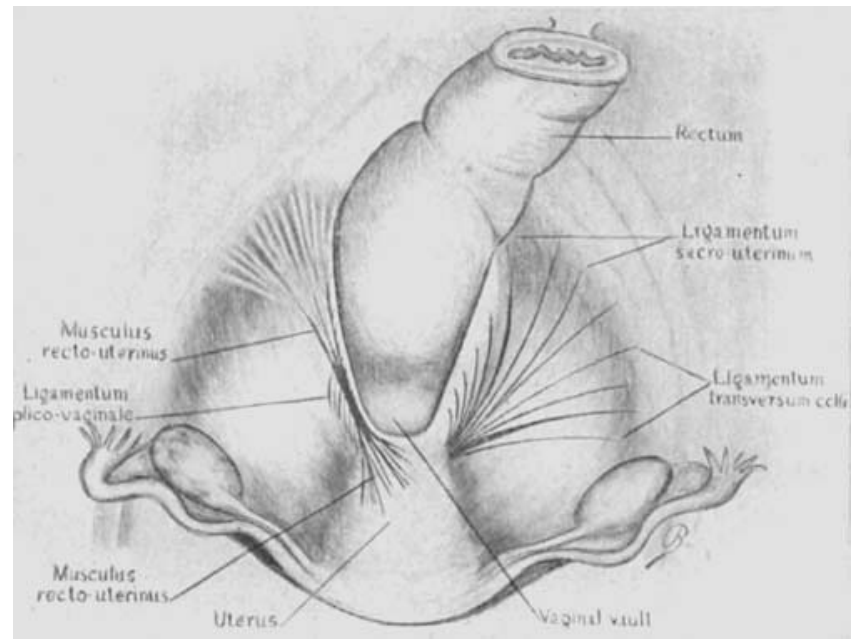

Fig. 10 Semi-diagrammatic drawing of female pelvic viscera viewed from above, uterus and adnexa having been drawn strongly forward. Position of potential ligaments are shown in black lines.

Traction forward on each sacro-uterine fold separately, tightened the peritoneum and raised its surface into a series of small ridges, that radiated toward the sacro-iliac junction and lateral border of the promontory, from the point where the fold disappeared, in a direction downward and inward to the middle of the second sacral vertebra at the edge of the rectum and reflection of the peritoneum upon it. The area raised on the right was triangular but did not extend so far laterally as given in figure 10; on the left side the raised area was narrower and less triangular than on the right. Traction backward on each fold 
tightened the peritoneum about the uterine cervix and vaginal vault, raised the cervix upward and backward, forced the fundus against the bladder and raised the vaginal vault.

Traction on the uterus to the right or left simply tightened the broad ligaments, peritoneum, and subperitoneal fibroelastic tissue without any special result.

Bodies embalmed in the usual way for dissection, or with a 10 per cent to a 40 per cent formaldehyde solution, will usually show the same result of traction on the sacro-uterine or rectouterine folds, and parametrial fibro-elastic tissue as above stated. The embalming fluids used, especially the formaldehyde solution, produced marked contraction of fibro-elastic tissue and such contraction produces bands which are rendered slightly prominent as peritoneal ridges, more or less above the general surface contour of the peritoneum, the results varying in different cadavers. Two female cadavers in the anatomical collection of the university show these facts beyond doubt.

Traction per vaginum downward and forward on the uterus depresses the sacro-uterine or recto-uterine folds and draws on the sacral attachments of the peritoneum, in the line of the folds. At the same time there is a coincident appearance of a prominent ridge in each dorso-lateral wall of the vaginal vault, corresponding to the position of the sacro-uterine and plicovaginal ligaments. There is a tightening of the subperitoneal tissue laterally as well as dorso-laterally to the uterus.

Reflection of the peritoneum lateral to the uterus and rectouterine fold. uncovers a mass of fibro-elastic tissue, through which run the branches of the hypogastric vessels, lymphatics, and nerves on their way to the uterus, vagina and bladder. Traction in different directions on this mass demonstrated its great elasticity as well as the intrinsic movements of the fasciculi and lamellae over each other. Careful dissection and examination with a moderately strong hand lens clearly defined a mass of interlacing fibers and fasciculi ensheathing the vessels and nerves and having an attachment to the fascia covering the levator ani, coccygeus and obturator muscles, as well as the presacral fasciae and peritoneum. Pulling on the fibro-elastic 
tissue from different points laterally and at the periphery; drew the uterus in the same direction; drawing the uterus toward the opposite side of the pelvis tightened the fibro-elastic mass which appears to radiate chiefly from the sides of the uterine cervix, while traction toward the middle of the inguinal ligament tightened the fibro-elastic mass laterally and posteriorly on the opposite side.

The examination of several autopsy specimens not only verified the above facts but revealed others (fig. 10). By carefully cutting through the peritoneum in the anterior part of the lateral wall of the recto-vaginal fossa, dissecting out the areolar tissue filling in the meshes of the fibro-elastic net-work and isolating a number of fibers, a dimpling of the peritoneal surface along the sacro-uterine fold could be produced by pulling downward on the fibers. Other fibers appeared to be attached further posteriorly in the vicinity of the sacrum. Pulling upward on the same fibers raised the vaginal vault or the cervix uteri. These experiments determined that there were two sets of fibers which entered or passed beneath the fold. One set passing from the sides of the uterine cervix backward, giving off fibers which were inserted into the stratum fibrosum of the peritoneum along the line of the fold, and others reaching the presacral fascia. The second set passed from the sides of the vaginal vault below the above and inserted into the stratum fibrosum along the anterior two-thirds of the fold. The study also determined that the meshes of the fibro-elastic network varied in size and irregularity. At times there was observed an apparent increase in the density of the fibro-elastic mass opposite to the cervix uteri and vaginal vault. At the periphery of the pelvic cavity just in front of the sacro-iliac articulation, the network appeared less dense. This condition was not always evident.

In cadavers that have been embalmed in the usual way and dissected, there will be found fasciculi passing laterally from the side of the uterine cervix, and forming a more or less distinct band which corresponds in position to the cardinal ligament or ligamentum transversale colli. Other fasciculi which pass 
backward beneath the sacro-uterine fold to reach the presacral fascia, correspond to the course of the so-called sacro-uterine ligament. The fibers sweeping downward from within the anterior two-thirds of the sacro-uterine fold to be inserted into the sides of the vaginal vault, are termed the 'plico-vaginal ligament.'

\section{b. Histological observations. Fixed material}

1. Adult 35 years old. Figure 11 is a photomicrograph of a portion of a transverse section of the sacro-uterine fold of a

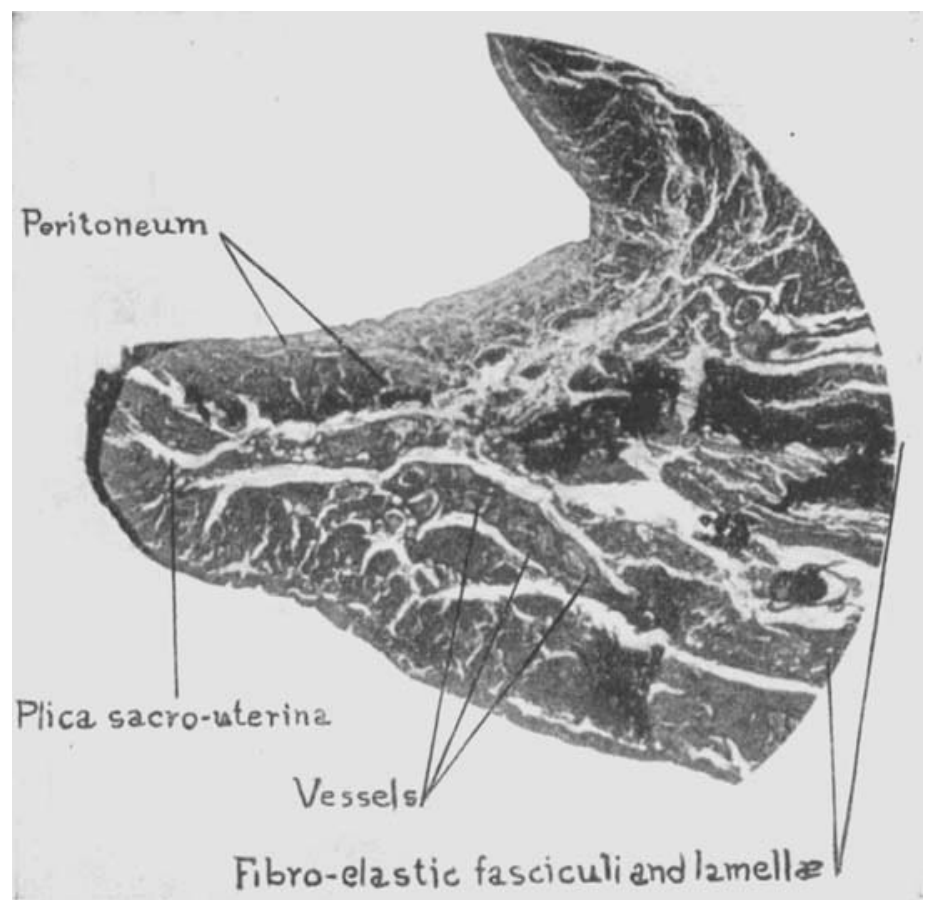

Fig. 11 Photomicrograph of a transverse section of recto-uterine fold at middle of anterior third, of a woman 35 years old. $\times 50$, oc. 2 ; obj. A.

woman 35 years old. The section is through the anterior third of the fold and includes the vaginal vault. The stratum fibrosum of the peritoneum is thickened and dense, the muscular fasciculi are abundant within it. 
The inner face of the dense fibrous layer shows a distinct tendency to break up into segments or divisions and most of them appear to be directly continuous with the fibro-elastic fasciculi or lamellae which sweep downward out of the fold to become part and parcel with the general fibro-elastic and perivascular network. Beneath the peritoneum therefore, the fibro-elastic

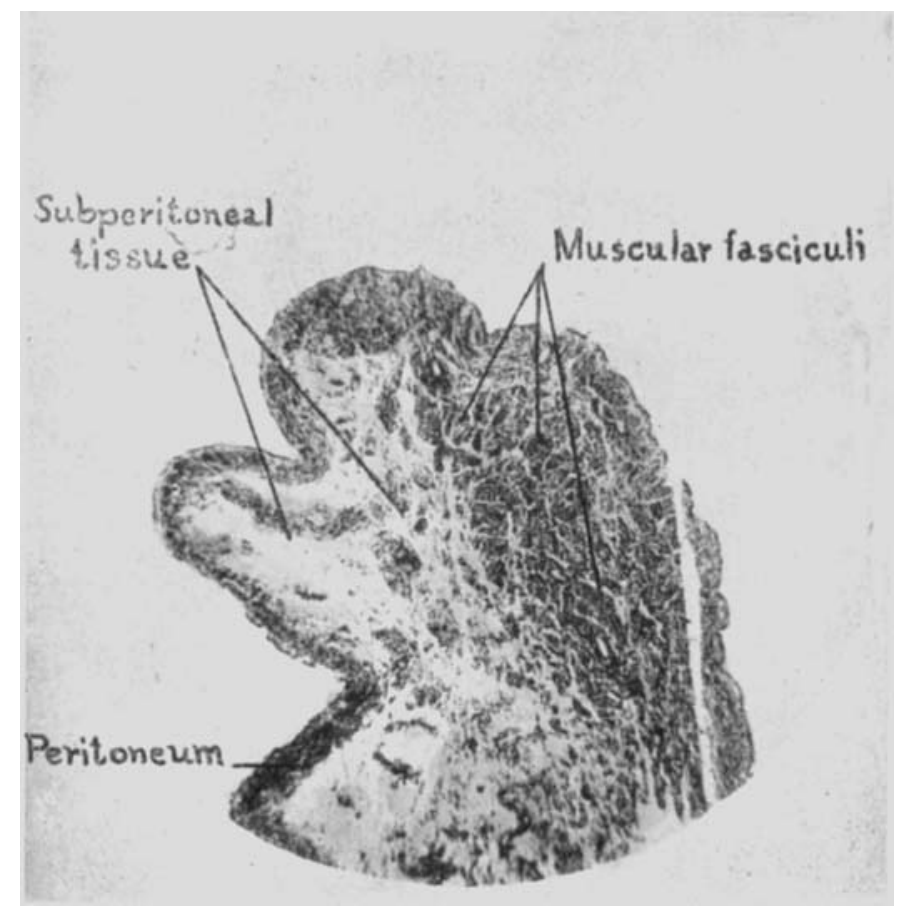

Fig. 12 Photomicrograph, transverse section of right recto-uterine fold in anterior part of middle third, of a child 10 years old. $\times 30$, oc. 4 ; obj. $\mathrm{A}^{2}$ (Zeiss).

tissue is dense and rich in blood vessels, lymph vessels and nerves. These fibro-elastic fasciculi and lamellae are parts of the plico-vaginal and sacro-uterine ligaments. The plicovaginal constituents end in the inner surface of the thickened peritoneum, and are the fibers which caused the dimpling in of the peritoneal surface of the fold in the experiments reported above. 
2. Child 10 years old. In sections (fig. 12) made at the middle of the sacro-uterine folds the peritoneum is thickened as usual and small fasciculi of muscle fibers are scattered sparsely through the slightly dense stratum fibrosum. On the border line between the latter and the subperitoneal tissue there is an aggregation of numerous large muscular fasciculi, small vessels and nerves. These fasciculi are surrounded by rather loose fibroelastic tissue, but the general character of it is such that it can be associated with the peritoneum, rather than with the supperitoneal tissue. In all probability, as growth continued, a

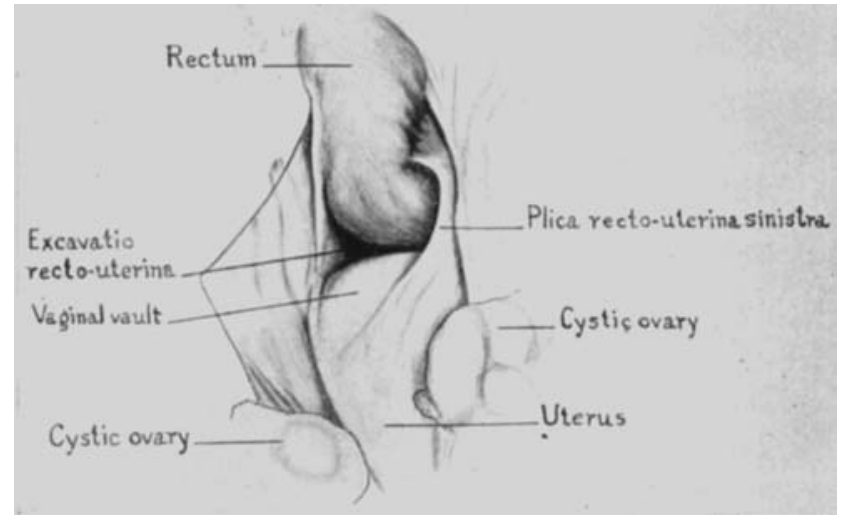

Fig. 13 Drawing showing the female pelvic viscera in an infant 40 days old. The uterus has been drawn forward. Made from the specimen studied.

greater condensation would take place and these elements would become more closely bound to the peritoneum. The sections are from behind the plico-vaginal ligament, and there are no fibers sweeping downward which could be taken for it. It is possible that a part of the above mentioned muscular fasciculi are those that accompany the sacro-uterine ligament.

3. Infant 40 days old. Figure 13 is a drawing of the pelvic viscera of an infant 40 days old. The specimen was cut in serial transverse sections. The left sacro-uterine fold was very prominent and terminated lateral and dorsal to the rectum. The right fold was much less prominent and terminated upon the lateral 
wall of the rectum. The structure of the folds as regards density of the tissues, was similar to thase of the adult 35 years old.

Figure 14 is a photomicrograph of a section through the middle of the right fold, the peritoneum is thickened, and in the flattened apex of the fold the intraplical fasciculi are very intimately connected to the deep surface of the stratum fibrosum;

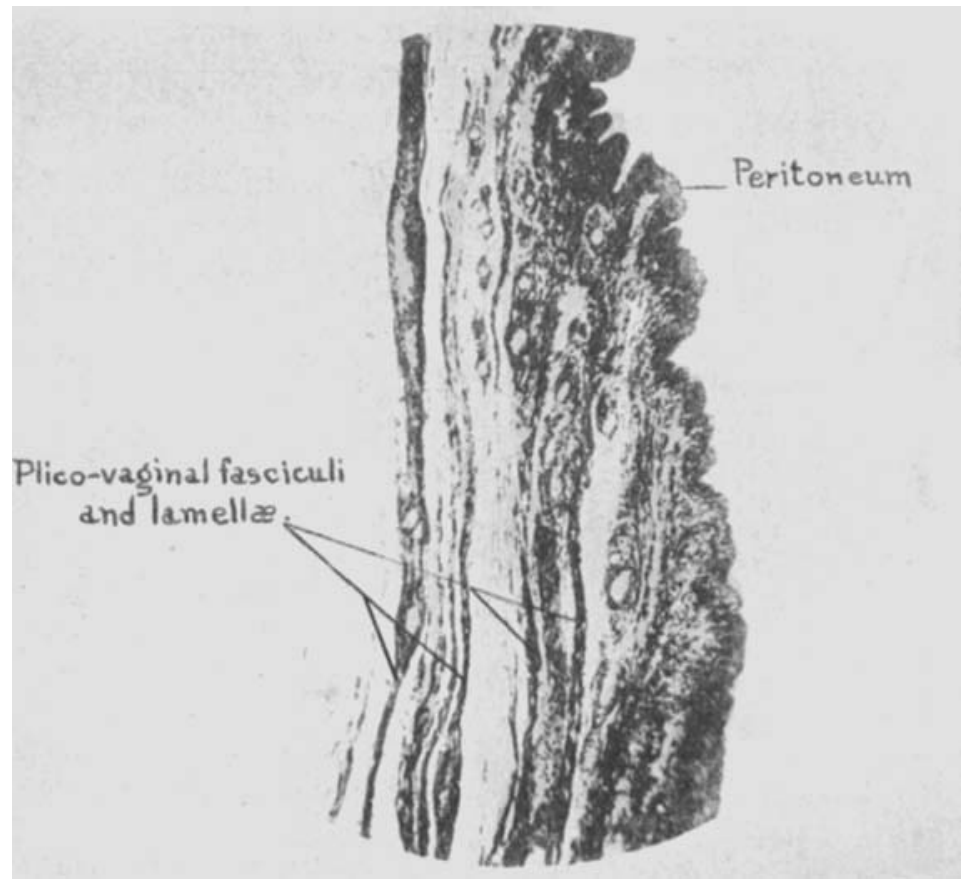

Fig. 14 Photomicrograph of a transverse section through the middle of the right recto-uterine fold, of an infant 40 days old. Note the dimpling of the peritoneal surface. $\times 50$, oc. 4 ; obj. A.

in the latter there are small muscular fasciculi. From their points of insertion into the peritoneum, the fibro-elastic fasciculi stream downward lateral to the recto-uterine fossa and become continuous with the general perivascular tissue.

The photomicrograph shows the wrinkling of the peritoneal surface and the fibro-elastic fasciculi can be definitely traced downward from their attachment to the stratum fibrosum. In 
both folds, these fasciculi are plico-vaginal and sacro-uterine, the former being the most evident.

The intraplical muscular fasciculi are those which in part probably accompany the sacro-uterine fibro-elastic fasciculi. To what extent these muscle bundles become associated with the peritoneum to constitute recto-uterine muscle bundles is not known.

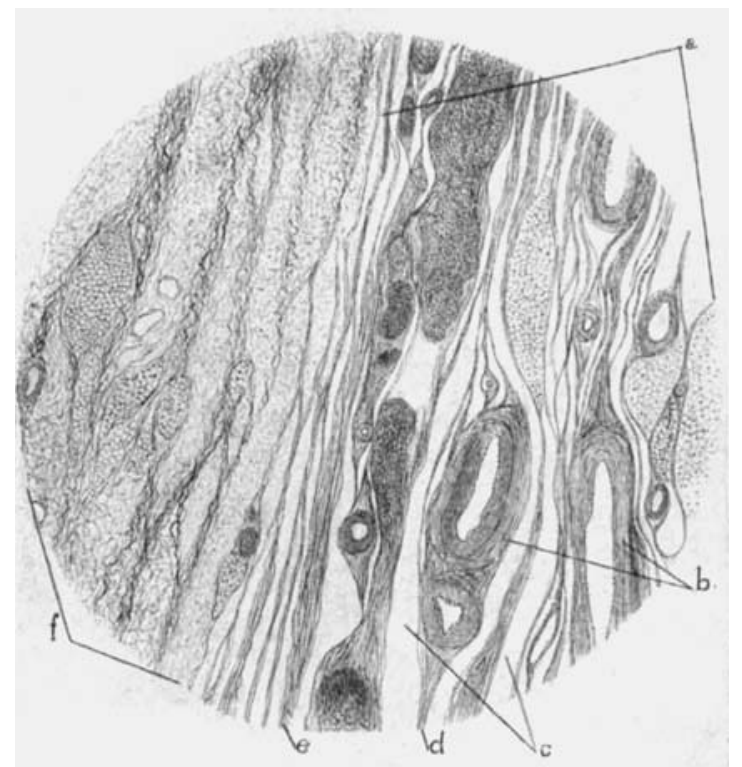

Fig. 15 Photomicrograph of a transverse section of a right plica rectouterina at anterior third, through plico-vaginal ligament (a), showing perivascular $(b)$ character of fibrous tissue, meshes $(c)$ between the lamellae $(d)$ and fasciculi $(e)$ filled with delicate areolar or adipose tissue (the former has not been filled in); lateral to ligament the tissue is distinctly fibro-elastic and areolar (f). Infant 40 days old $\times 88$ diam., oc. 2 ; obj. A. Reduced to one-third.

Figure 15 is a drawing of the paraplical tissue below the point shown in figure 14. It shows the perivascular character of the fibro-elastic fasciculi and lamellae. The tissue shown here is a part of the plico-vaginal ligament. Particular attention should be given to the manner in which the mesh-work is formed-by division and union of fasciculi and lamellae and 
how they enclose the vessels. The whole is representative of the arrangement throughout the parametrial, paravaginal and paraplical network. It has been observed that the lymphoglandulae are not as a rule enveloped by the fibro-elastic lamellae, but project into a mesh, being only attached at the hilus to a lamella, which immediately envelops the vessels entering or leaving it. At least this has been the case in a number of instances. The capsule of the gland is continuous with the lamella at the hilus.

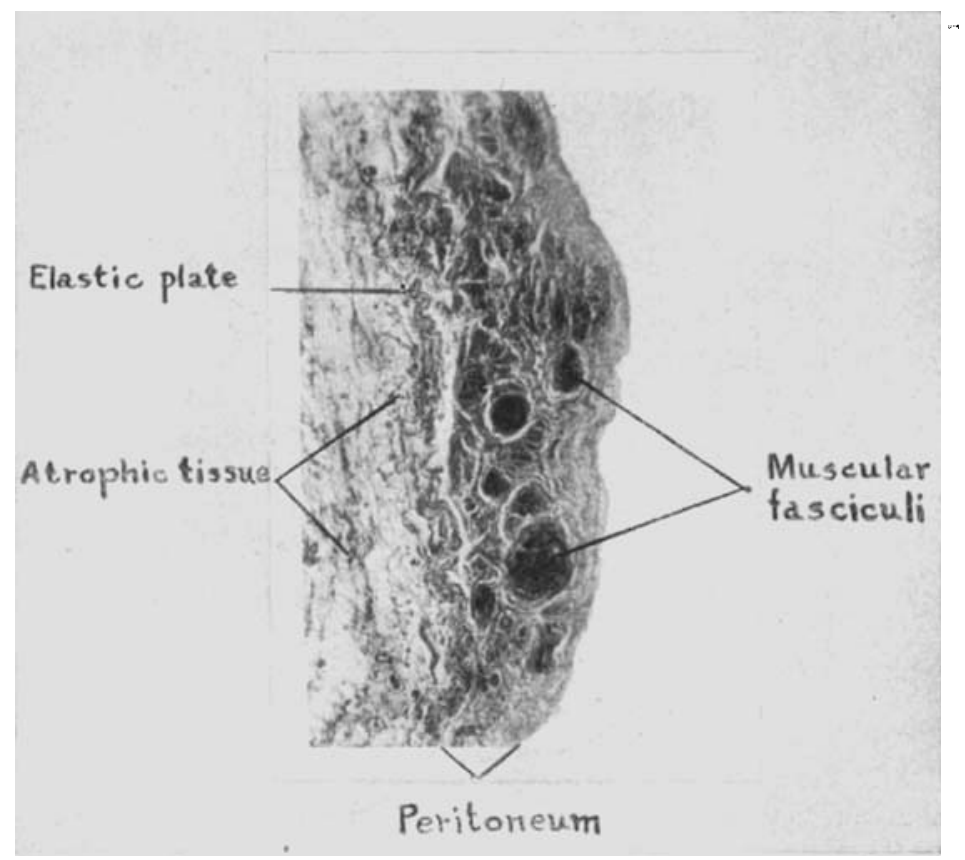

Fig. 16 Photomicrograph of a transverse section of a sacro-uterine fold at the posterior third, of a woman 65 years old. $\times 50$, oc. 2 ; obj. A.

The meshes of the network are filled with delicate areolar or adipose tissue, as shown in figure 15, where a part of the meshes have not been filled in, to better demonstrate the fibro-elastic network. Lateral to the plico-vaginal fasciculi, the tissue is distinctly elastic and areolar.

4. Adult 65 years old. Figure 16 is a photomicrograph of a portion of a transverse section of a plica sacro-uterina of a woman 
past the menopause. The peritoneum still remains much thickened, the bundles of the recto-uterine muscle are very distinct, and the subperitoneal fibro-elastic tissue shows distinct senile atrophy. The general looseness of the tissue is noticeable and adipose tissue is more abundant than at the other ages considered above.

Figure 17 is a drawing of a portion of the peritoneum in the section from which figure 16 was made, but more highly magnified. The muscle bundles have been drawn in heavy black to

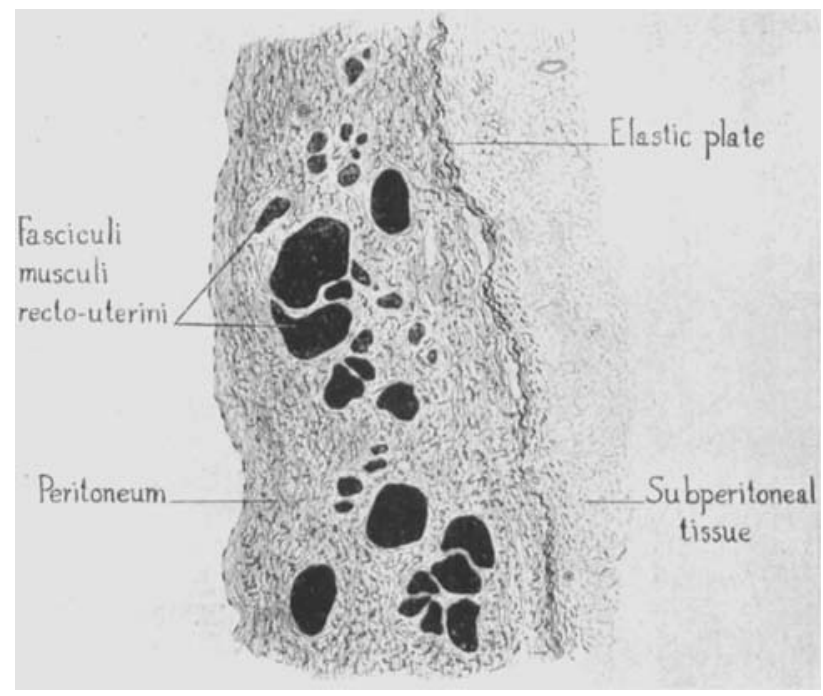

Fig. 17 Photomicrograph of part of a transverse section of plica sacrouterina at posterior third, showing distribution of fasciculi of recto-uterine muscle, elastic plate and subperitoneal connective tissue in a woman 65 years old. $\times 88$. Reduced to one-third.

emphasize their abundance. At the inner limit of the dense stratum fibrosum there is a distinct layer or plate of elastic tissue. Figure 18A shows this layer as brought out by Weigert's elastic tissue stain. This elastic plate lies to the inner side of the thickened fibrous stratum of the peritoneum, and becomes much thinner at the periphery of the plical area where it approaches quite close to the mesothelium; it appears to limit internally the stratum fibrosum. Whether or not this layer will be of value in 
determining the relation of the recto-uterine muscle to the peritoneum remains to be seen. Figure 18B illustrates the abundance of elastic fibers in a fasciculus of the recto-uterine muscle of the same section.

5. Adult 83 years old. Figure 19 shows one of a transverse series of sections through a sacro-uterine fold of a woman 83 years old. The section has been taken from the fold at the middle of the middle third. The fibrous stratum of the peritoneum is thickened as usual, and immediately beneath the mesothelium there is a distinct layer of undulating fibers $(A)$, that separates the stratum containing the muscular fasciculi from the mesothelium. The fibers of the deeper layer $(B)$ are more irregular and broken, receiving the insertion of the
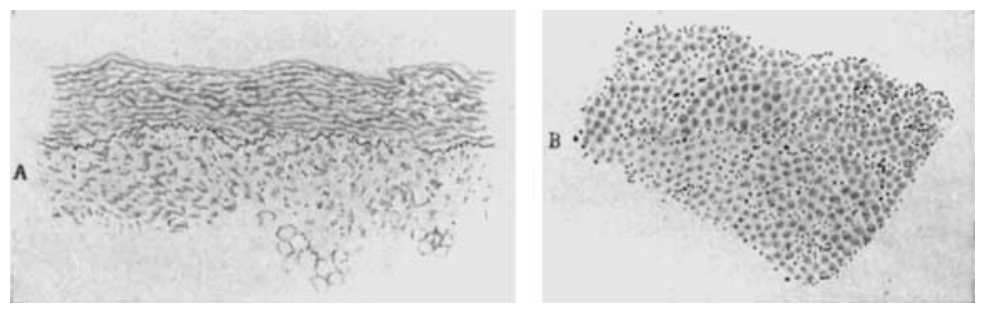

Fig. 18 A. Section of peritoneum from sacro-uterine fold of a woman 65 years old. B. Transverse section of a recto-uterine muscle, bundle, showing abundance of elastic tissue. Weigert's elastic tissue stain. $\times 90$ diam. Camera lucida drawing. Reduced one-half.

plico-vaginal fibers which are well shown in the sections. The fibro-elastic tissue is less compact than in the infant 40 days or the woman 35 years old on account of the senile atrophy present. Weigert's elastic tissue stain also brought out a greater irregularity in the distribution of the elastic fibers. The elastic plate so well defined in figure 17 is missing here, although a very irregular line of elastic fibers is present. The stain has also brought out a greater amount of elastic tissue in the submesothelial fibrous layer that was not noticeable in the sections from which figure 16 was made. In figure $18 \mathrm{~B}$ there is shown an abundance of elastic fibers in relation with the muscular fasciculi and it is to be noted that they are between the elastic plate 


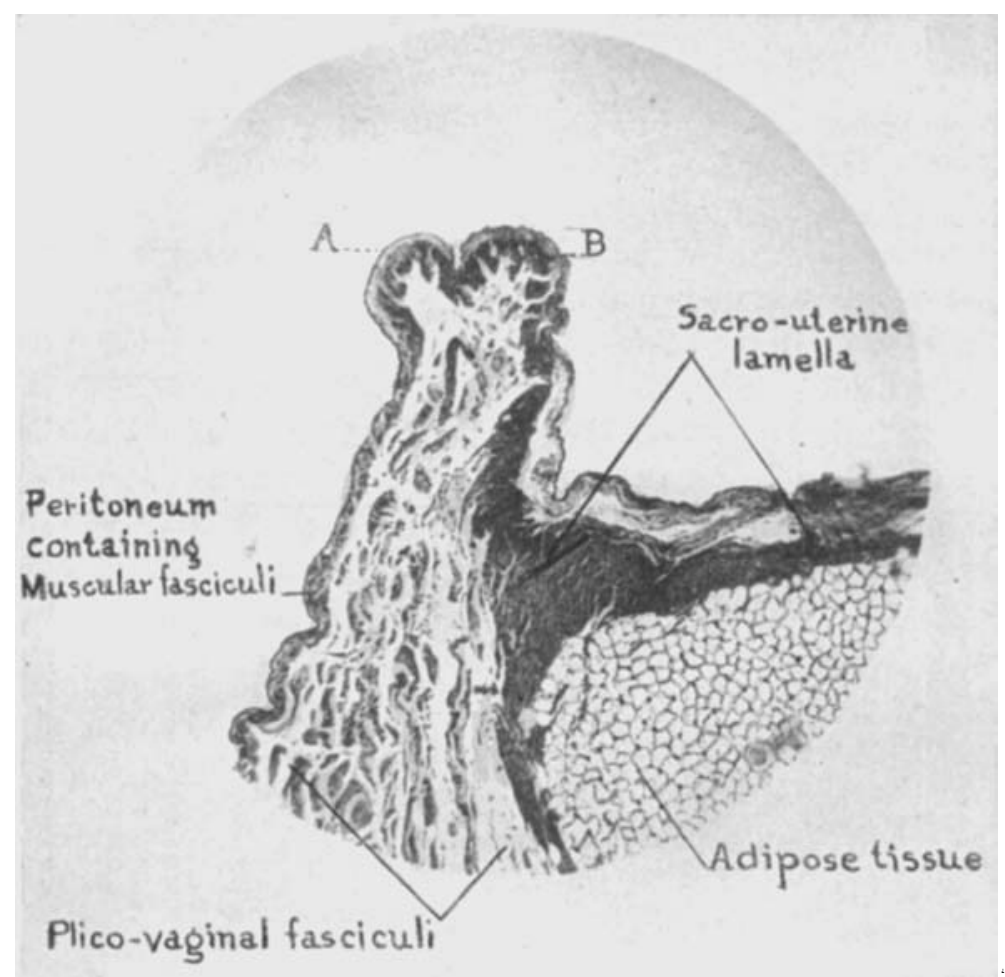

Fig. 19 Photomicrograph of a transverse section of sacro-uterine fold at middle of middle third, in a woman 83 years old. $\times 30$, oc. 2 ; obj. $\mathbf{a}^{2}$ (Zeiss).

and the mesothelium. Beyond the area of distribution of the fasciculi of the plico-vaginal and sacro-uterine ligaments, adipose tissue is very abundant, scattered through which is a varying but meager number of fibro-elastic lamellae that have been cut across.

\section{VARIATIONS}

It is well known from observations made in the dissecting room and at autopsies, that the peritoneal surface contour of the pelvic cavity and relative size of the pelvic viscera are subject to considerable variation; at times to marked asymmetry. The bones forming the pelvic wall may vary so as to render the cavity narrow and relatively deep, or broad and relatively 
shallow. The muscles may be much better developed in some individuals than in others, and the amount of fibro-elastic tissue may likewise vary.

Every gynecologist knows that the perineal body may be large and strongly constituted in some women, or feeble and scarcely recognizable. The muscles guarding the pelvic outlet are very strong and capable of affording ample support to the pelvic organs in some individuals, in others they are poorly developed and incapable of withstanding continued strain. These variations bespeak for a general habitus which may indicate a predisposition to the persistent maintenance of the norm, or an easy deviation from the same. The plicae sacro-uterinae are no exception to the rule. In certain cases they are strongly developed and very prominent and symmetrical or asymmetrical; at other times they apparently are entirely absent, or a short plica may be present on each side near the uterus. But even when visibly absent, they are potentially present, for forward traction on the uterus produces them. Or a distended rectum, by carrying the peritoneum away from the pelvic wall, will produce them or convert sacro-uterine into recto-uterine folds. The position of the rectum also influences the character of the folds. If the rectum is median in position, both folds are usually sacro-uterine; if that organ is sinistral, the corresponding fold will be recto-uterine and the opposite will be sacro-uterine and vice versa when the rectum is dextral in position. Histological examination reveals similar variations, both as regards quantity and symmetry, in the uterine supports.

\section{EXPERIMENTS}

In an anesthetized cat, with the abdomen opened and the pelvic organs exposed to view, the uterus and bladder have been observed to contract more or less intermittently as peristaltic waves passed down the rectum. Though slight, these contractions were unmistakable.

In the animal studied, the rectum happened to be strongly distended with fecal matter opposite the recto-vaginal fossa and the point of attachment of the recto-raginal folds. The 
viscus was stretched in the directions of both its primary and secondary axes. The recto-vaginal folds were large and exhibited occasional contractions, which feebly raised the vaginal vault. After the sigmoid colon had been severed and the fecal contents expelled, it was observed that the intestine slowly contracted and sank lower in the pelvis. During this descent the recto-uterine folds diminished in size and the vaginal vault sank carrying the uterus with it. The rectum was then injected to reproduce the effect on the vaginal vault through traction on the recto-vaginal folds. The rectum was clamped behind the free extremity of the vagina, and the rectum slowly distended with water. As a consequence, the rectum pulled cephalad on the folds raising the vaginal vault and carrying the uterus toward the abdominal cavity. These observations in the cat suggested, first, that the distended rectum mechanically raises the vaginal vault when its fecal contents are passing caudalward and thus prevents compression of the organs of reproduction; second, the act in all probability excites a reflex contraction in the uterus which participates in the act through the recto-uterine muscles; third, that the uterus can automatically raise itself through contraction of the recto-uterine muscles in the recto-vaginal folds.

These experiments were repeated on a cadaver of an infant 40 days old. The uterus was raised as before by traction on the right recto-uterine fold by distention of the rectum, and at the same time the partial conversion of the left sacro-uterine fold into a recto-uterine fold was accomplished. Hence the uterus can automatically raise and tilt itself ventrad in primates, or be raised mechanically by the recto-uterine folds when the rectum is distended. Or, distention of the rectum may cause reflex contractions of the uterus. When the sacro-uterine folds are present and the rectum is median in position, the uterus must act alone through a reflex. If the rectum is sufficiently distended, it can convert sacro-uterine folds into recto-uterine folds. When the uterus is raised through traction or contraction of the recto-uterine muscle, the sacro-uterine fold is tightened, the plico-vaginal ligament is pulled upward carrying the vaginal vault with it. 


\section{THE MUSCULI LEVATORES UTERI}

No reference has been made to the muscular tissue that passes off laterally from the uterus to be dispersed through the fibroelastic tissue filling the subperitoneal space lateral to the uterus. Microscopical examination of the parametrial tissue shows that smooth muscle is abundant about the point of insertion of the fibro-elastic tissue into the sides of the uterine cervix, and that it diminishes in abundance as it is traced laterally and posteriorly. The fibers appear to be inserted into the perivascular tissue, the fibrous fasciculi and fasciae of the nearby muscles, but their actual termination has not been determined. Direct continuity of the recto-uterine muscles with the muscularis uteri is established. This muscular tissue extends from the uterus into the adjacent tissue at an early embryonic period. These muscles, one on each side of the uterus, enable that organ to automatically raise itself on the fibroelastic suspensorium. By their more or less intermittent contractions, they probably become one of the chief agents in aiding the venous circulation in the peri-uterine venous plexuses; the pelvic diaphragm being accessory to the act.

\section{DISCUSSION}

In taking up the discussion of the uterine ligaments, it is necessary to consider briefly the mechanical supports of the uterus in order to fully appreciate the part which the fibroelastic or so-called perivascular tissue plays in the process.

The mechanical supports of the uterus will be considered in the following order:

1. The levator ani and its superior fascia.

2. The peritoneum.

3. The fibro-elastic tissue filling in the interval between the two first mentioned.

Gynecological text-books usually speak of the pelvic floor as a support of the uterus. Fothergill (15) and Cameron (13), the former preceding the latter, have described the levatores ani as forming 'a tunnel' on each side of the vagina and being attached 
to it at its lower part. Cameron (13) is quite right when he states that the uterus which is above the vagina-the latter not receiving any direct support in its upper part from the muscular diaphragm-has no support from these muscles. The superior fascia of the levatores ani does not prevent the descent or ascent of the uterus. He asks why it is that the superincumbent intestines do not crowd the uterus and the vagina downward concertina-like? Cameron (13) rightly concludes that some other structures prevent this, which according to him are the 'perivascular fascia' and the blood vessels.

It is certain that the pelvic diaphragm plays a large part in supporting the pelvic viscera, and indirectly the descent of the superincumbent intestines, which when normally suspended by their mesenteries exert very moderate pressure. The normal supporting function of the pelvic diaphragm may be likened to a foundation upon which a superstructure rests, and which when it ascends or descends, carries the superstructure with it. By virtue of its contractile power and up and down movement, it also aids in preventing venous stasis within the pelvic plexuses, besides fulfilling other functions.

The superior fascia of the levatores ani steadies and aids in maintaining the cephalic extremity of the vagina and uterus in their median position, and also gives support and attachment to the parametrial fibro-elastic mesh-work. The peritoneum may be regarded as a support in the sense that it envelopes the pelvic organs as a sheet, forming lateral folds for the support of vessels and the adnexa uteri, maintaining the uterus in its normal anatomical position, and preserving this relation in its physiological excursions. Besides, as Cameron (13) states, it furnishes the superior attachment of the 'perivascular tissue.' The sacro-uterine or recto-uterine fold of the peritoneum has a varying degree of usefulness, which has already been partially stated and will be referred to again. Cameron (13) denies that these folds exert any supporting influence on the uterus, but laid great stress on the 'perivascular tissue,' which is weakest anteriorly lateral to the bladder, and between the folds of the broad ligaments; but increases in thickness as it is traced back- 
ward, and is greatest in amount opposite the broad ligaments and the sacro-uterine folds. Its attachments, to quote Cameron (13) again, are as follows: "Above to the peritoneum, below to the pelvic sheaths of the levator ani and coccygeus, externally to the obturator fascia, and higher up to the periosteum of the innominate bone, while internally it blends with the connective tissues of the viscera. Its attachment to the lateral pelvic wall is rendered further secure by the fact that the parietal branches of the hypogastric vessels pierce the pelvic parietes in order to reach their respective destinations, and in doing so their sheaths blend with the surrounding bony and muscular structures." It is admitted that the "main trunks of the hypogastric vessels, in their descent on the lateral wall of the pelvis, are bound down to the latter by dense areolar tissue." Cameron (13) has somewhat over-estimated the relative size of the vessels passing to the bladder, uterus and vagina. The main vessels are large and well anchored to the lateral wall of the pelvis, and their visceral branches are supported and surrounded by the fibro-elastic tissue in part. These vessels are not a factor in the support of the uterus, and the ovarian vessels enter too high to be a support; and besides, it is to be expected that vessels which are to be put to greater or less stretching, will be more or less tortuous in their course.

The parametrial tissue contains the peri-uterine venous plexuses, which must not be kept on a strain or under continual compression. It is necessary to again call attention to the abundance of the lymphatic vascular net-work, and the numerous nerves that permeate this region. The round ligaments are of doubtful importance as uterine supports, and Fothergill (15) has pointed out that they are essentially embryonic in function. Cameron (13) has given importance to the obliterated hypogastric arteries as a pelvic support. They may act feebly. They are essentially embryonic in function. Cameron (13), after his discussion of the importance of the different pelvic supports, sums up by stating that "the perivascular fascia, plus the pelvic sheaths of the levator ani and coccygeus muscles, are the most important." 
Montgomery (8) considers that the supports of the uterus are not ligaments in the ordinary sense, but consist of connective tissue, into and through which run prolongations from the uterine muscular structure, so that the organ is virtually sustained by muscular action. But he confounds the movements of the pelvic diaphragm with true intrinsic uterine activity, such as it is capable of exerting through the musculi levatores uteri. Its excursions upward and downward with 'every respiratory' movement, depends upon the action of the respiratory mechanism.

Mackenrodt (3) lays great stress on a band of connective tissue, the ligamentum tranversale colli, as of great physiological importance in maintaining the normal position of the uterus. He recognizes that the lower opening of the pelvis is closed by pelvic fascia, which sends firm bands to the cervix and vagina; that the cervix is held fast in its embryological position by ligaments, while the uterine body is kept in position by its own weight and intra-abdominal pressure--not by ligaments. Evidently this knowledge of the 'firm bands' was acquired through the dissection of embalmed material. He says that fibers coming from the pelvic fascia to the side of the cervix are to be sharply defined from the sparse connective tissue between the folds of the broad ligament. These, he states, form a band that is the chief means of holding the uterus in position. Another statement is that this band or ligementum trensversale colli carries the arteria uterina in its upper part (vide fig. 20).

Ovenden (12), in her dissections, found very "little connective tissue between the layers of the broad ligament, but at the level of the cervix, however, a thick band can be felt between the two layers of the peritoneum. It is wedge-shaped in section; the apex of the wedge is directed upward and is just above the level of the point of entrance of the uterine artery. Traced to its distal attachments, this band is found to be formed from strong fibrous connective tissue, continuous with that which surrounds the pelvic blood vessels, and also that which comes through the sacro-sciatic notch. Some of the fibers appear 
also to be attached to the sides of the third and fourth pieces of the sacrum."

Mackenrodt (3) considered that the ligamentum transversale colli has its central attachment at the supra-vaginal portion of the cervix. Ovenden (12) considers it inserted partly into the vaginal vault and lateral fornix, besides into the sides of the uterus for a short distance below the point of entrance of the uterine artery (vide figure 20).

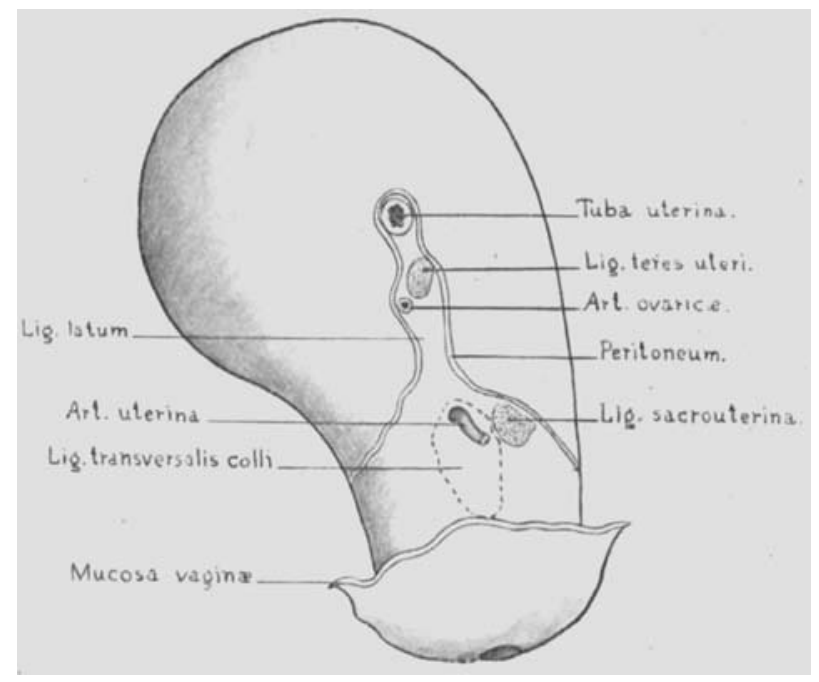

Fig. 20 Side view of uterus (as removed by vaginal hysterectomy) showing insertion of ligamentum transversale colli of Mackenrodt (after Ovenden).

These facts agree with the observations reported in the earlier part of this paper. Ovenden (12) is correct in considering that the whole mass is not inserted into the uterus, as Mackenrodt (3) asserts; and also that the sacro-uterine ligament blends with the ligamentum transversale colli near its insertion into the uterus. The plico-vaginal ligament attached to the vaginal vault becomes continuous with the sacro-uterine ligament. It is to be noted that these observations make these three ligaments continuous at their insertion into the sides of the cervix and vaginal vault. 
It must be mentioned that Emmet (23) and Schauta (24) have laid emphasis on the importance of the part played by this pelvic connective tissue in maintaining the normal position of the uterus, although they did not ascribe this function to a particular band.

Specimens from the cut ends of the so-called sacro-uterine ligaments, as severed from their attachment into the sides of the uterine cervix at the time of operation for utero-vaginal prolapse in elderly women, were submitted to the writer by Dr. George B. Somers (25) for microscopical study. One ligament, evidently cut closely to the uterus, showed a great preponderance of smooth muscular tissue over the fibro-elastic; the other, much less muscular and chiefly fibro-elastic tissue. Ovenden (12) states that in microscopical sections the ligament consists largely of fibrous tissue, through which are scattered a good many bundles of smooth muscle fibers.

None of the writers have attempted to explain the marked elasticity that is inherent in the pelvic structures, not how or why the uterus can be pulled down to the introitus vulvae or to the exterior, and when released will slowly and completely return to its normal position in the pelvic cavity without further manipulation. From the experiments, dissections and observations reported in this paper, it now becomes necessary to describe the fibro-elastic suspensorium uteri, which accounts for all of the phenomena that have thus far been observed and reported.

If a square piece of thin paper be taken and folded over two or three times, cut one-half across first on one side and then on the other, when opened up it will appear as in figure $21 \mathrm{~A}$. Traction applied in direction of the arrows or diagonally at the corners, will open up a mesh-work as in figure $21 \mathrm{~B}$. Release the paper and it will instantly return to a state of rest as before the traction was applied (fig. 21A). This paper possesses elasticity and an inherent tendency to return to a state of rest, but the phenomena are in a reverse order to that observed in the fibroelastic mesh-work of the suspensorium uteri. 
Figure 22A represents the fibro-elastic mesh-work filling the parametrial and paraplical space in a state of physiological tonus or rest (potential ligament). It is an open mesh-work,

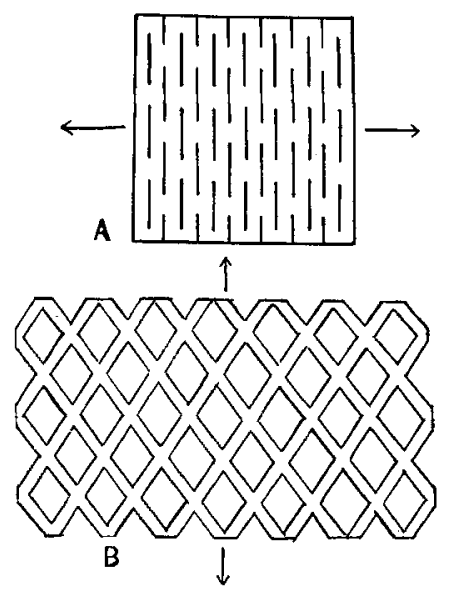

Fig. 21 A piece of tissue paper folded and cut $(A)$ so as to form a mesh work (B) that possesses elasticity and an inherent tendency to return to a state of rest as in $A$, but in a reversed order to that of the fibro-elastic mesh-work of the suspensorium uteri.
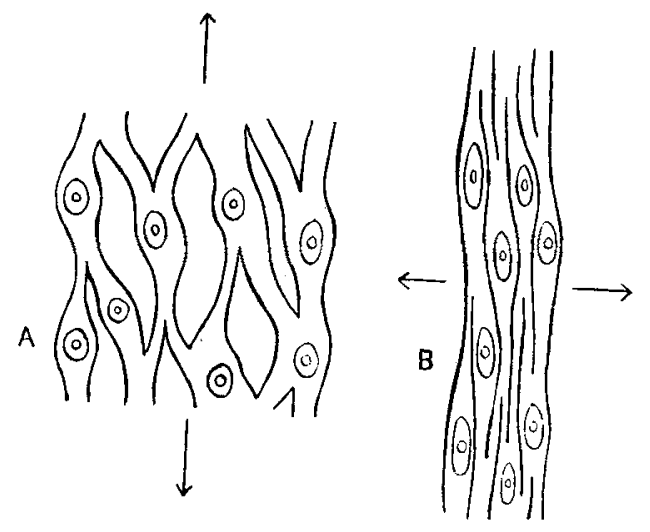

Fig. 22 Drawings illustrating the effect of traction upon fibro-elastic meshwork. (A) Fibro-elastic mesh-work in state of physiological tonus or rest (potential ligament); $(B)$ fibro-elastic mesh-work in state of traction (actual ligament). 
the meshes of which are filled with areolar or adipose tissue. If traction is made as indicated by the arrows, the condition seen in figure 22B will result, the fasciculi and lamellae will be approximated and a transitory ligament will form. Remove the traction and by virtue of the inherent elasticity or resiliency the mesh-work returns. These simple experiments demonstrate the mechanism of the fibro-elastic suspensorium uteri.

The fibro-elastic network is like a net that has been symmetrically attached at a periphery and inserted into the two sides of a body, which is suspended by it. Traction downward on this body approximates the threads of the net which appear to diverge from the point where they are attached to it. If the body is released it is immediately carried upward until the inherent elasticity of the netting is satisfied, when a state of rest is established. The threads of the net no longer appear divergent at the sides of the body for they appear as a part of the net-work.

Such is the author's conception of the manner in which the uterus is suspended by the fibro-elastic tissue of the parametrial and paraplical space and which is aided by the pelvic diaphragm and peritoneum. From what has already been said in this paper, the full import of the argument should be clear to all.

The normal workings of the suspensory mechanism is best observed in the virgin pelvis. Various factors begin to operate at the time of puberty, which may sooner or later weaken the power of the uterine or vaginal supports. Aside from the weakening effects of parturition, with possible injury to the pelvic floor, the pernicious effects of chronic constipation and tight lacing have to be taken into account. These slowly cause the fibro-elastic tissue to give away with loss of the normal resiliency or tone.

The writer agrees with Fothergill (15) in stating that prolapsus uteri may not occur even in long standing laceration of the perineum, providing the fibro-elastic suspensorium retcins its tone. In the section on variation, the writer has pointed out that the relative size and strength of parts may vary greatly in the same and different individuals. A weak pelvic floor will 
not bring about prolapsus uteri if there happens to be a well developed fibro-elastic suspensorium; on the other hand, a strong pelvic floor will delay a prolapse when a weak suspensorium is present. A lacerated perineum is always a source of danger. The applied facts should be clear.

With Cameron (13), the writer suggests that an attempt must be made to restore the weakened fibro-elastic support, if success in treatment of prolapse and mal-positions of the pelvic organs is to be obtained.

\section{CONCLUSIONS}

The material studied for the preparation of this paper seems to justify the following deductions and problems:

The plicae sacro-uterinae or recto-uterinae are the homologues and analogues of the plicae recto-vaginales of quadrupeds.

The musculi recto-uterini of the higher Primates are the homologues and analogues of the same in quadrupeds.

The plicae recto-uterinae and their intimately associated musculi recto-uterini are primitive, appearing in the vertebrate series before the fibro-elastic suspensorium uteri or a well developed musculus levator uteri.

The suspensorium fibro-elasticum uteri has been gradually evolved with the assumption of the erect attitude in locomotion, and is not present, or is present only in a very rudimentary way in animals which habitually assume the horizontal attitude in locomotion. If present in a rudimentary or primitive form, it is only concerned in maintaining to a greater or less extent the cephalic portion of the vagina.

In woman, and the females of the higher Primates at least, the supports of the uterus are three in number, namely:

1. The suspensorium diaphragmaticum (pelvis).

2. The suspensorium peritoneale.

3. The suspensorium fibro-elasticum.

The latter being the chief and essential support, the others being accessory.

The suspensorium fibro-elasticum consists of a fibro-elastic network supporting vessels and nerves, and contains the poten- 
tial ligaments of the uterus and vagina. The meshes of the network are filled with aerolar tissue which permit the fasciculi and lamellae to move freely over each other.

The potential ligaments are the ligamentum transversale colli of Mackenrodt, ligamentum sacro-uterinum, and the ligamentum plico-vaginale, which become actual through traction on the uterus and vaginal vault.

The three above-named ligaments are directly continuous with each other at the sides of the uterine cervix and vaginal vault and with the general fibro-elastic network to the periphery.

The fibro-elastic network in a state of physiological rest forms an open mesh-work and possesses an inherent tendency to return to a state of rest after traction on the uterus or vaginal vault has ceased to operate, and neutralizes or minimizes downward pressure through this same property.

The fibro-elastic network in a state of rest prevents compression of the venous and lymphatic vessels by preventing collapse of their walls. All traction upon it more or less compresses the vessels and it hence becomes an aid to the venous and lymphatic circulations.

The upward and downward movements of the suspensorium diaphragmaticum augments the action of the suspensorium fibro-elasticum in aiding the pelvic circulation, and in this way it is analogous to the thoracic diaphragm.

The suspensorium fibro-elasticum permits the uterus being depressed to the introitus vulvae. The return of the uterus to its normal position being first aided by the diaphragmatic funnel, and completed by the suspensorium fibro-elasticum.

The musculi levatores uteri are derived from the muscularis uteri and constitute a mechanism by which the uterus can automatically raise itself on the suspensorium fibro-elasticum. By its more or less rhythmical or intermittent contractions, in conjunction with the muscularis uteri, it aids the venous and lymphatic circulation in the respective peri-uterine plexuses.

The plicae sacro-uterinae or recto-uterinae, with the intimately associated musculi recto-uterini, lifts the uterine 
cervix and vaginal vault upward and backward, through stimuli received from a distended upper rectum or from other sources.

Those fasciculi and lamellae of the fibro-elastic network that arise from the presacral fasciae and along a plica sacro-uterina, and which have a general trend to the vaginal fornix and uterinc cervix, behind and below the point of attachment of the ligmentum transversale colli, constitute the ligamentum sacrouterinum, potential or actual (transitory).

Those fasciculi and lamellae of the fibro-elastic network arising from the fasciae of the levator ani, obturator, or sheath of the hypogastric vessels in the lateral wall of the pelvis, and with a general trend toward, and attachment to the side of the uterine cervix below the uterine artery, and above the ligamentum sacro-uterinum, constitute the ligamentum transversale colli potential or actual (transitory).

Those fasciculi and smaller lamellae arising from the stratum fibrosum of the peritoneum of the anterior two-thirds of a plica sacro-uterinum or recto-uterinum, and inserting into the sides of the vaginal vault below the ligamentum sacro-uterinum constitute the ligamentum plico-vaginale, potential or actual (transitory).

Any weakening of the suspensorium diaphragmaticum, which will result in a falling of the pelvic floor, or when coupled with a lacerated perineum, will result sooner or later in an overstretching, and a giving way of the suspensorium fibro-elasticum, and must result in a vaginal or uterine prolapse, or malposition of the uterus, with consequent disturbance of the fibroelastic and muscular mechanisms, which will be rendered more or less inoperable, with resulting venous stasis and increased weight of the pelvic viscera.

In conclusion, the writer desires to acknowledge his indebtedness to Prof. A. W. Meyer, for advice, and to Prof. William Ophüls and Dr. Edgar D. Downing, for the permission to examine and use material from the autopsy room; to Prof. E. C. Dickson for the preparation of the photomicrographs.

The work was begun while the author was connected with the division of anatomy. 


\section{LITERATURE CITED}

(1) Kocks, J. 1880 Die Normale und Pathologische Lage und Gestalt des Uterus. Bonn.

(2) Hart, J. Berry 1880 The structural anatomy of the female pelvic floor. Edinburgh.

(3) Mackenrodt, A. 1895 Ueber die Ursachen der normalen und pathologischen Lagen des Uterus. Archiv f. Gyn., 48, p. 393.

(4) Holl, M. 1897 Die Muskeln und Fascien des Beckenausganges. Von Bardelebens Handbuch der Anatomie des Menschen, Bd. 7, Jená.

(5) Harman, N. Bishop 1898 The pelvic splanchnic nerves. Journ. Anat. and Physiol., vol. 33, p. 386 .

(6) Thompson, P. 1900 The pelvic diaphragm. Studies from the Anat. Dept. of the Owens College, vol. 2.

(7) Deaver, John B. 1903 Surgical Anatomy, vol. 3.

(8) Montgomery, E. E. 1903 Practical Gynecology.

(9) Stony, R. A. 1904 The anatomy of the visceral pelvic fascia. Journ. Anat. and Physiol., vol. 38.

(10) Derry, Douglas E. 1907 On the real nature of the so-called pelvic fascia. Journ. Anat. and Physiol., vol. 42, 1st Pt.; Oct.

(11) Paterson, A. M. 1906 The mechanical supports of the pelvic viscera. Brit. Med. Journ., Dec. 15, p. 1701.

1906-07 The mechanical supports of the pelvic viscera. Journ. Anat. and Physiol., London, 41, p. 93.

(12) Ovenden, Elia G. 1906-07 The lateral fixation of the cervix uteri. Jour. Anat. and Physiol., London, 41, p. 308.

(13) Cameron, John 1907-08 The fascia of the perinaeum and pelvis of the female, with special reference to the mechanical supports of the pelvic viscera. Journ. Anat. and Physiol., 42, Ser. 3, p. 438.

(14) Sмith, G. Elliotт 1908 Studies in the anatomy of the pelvis with special reference to the fasciae and visceral supports. Pt. 1, Jour. Anat. and Physiol., Jan., p. 198.

(15) Fothergill, W. E. 1908 The supports of the pelvic viscera. A review of some recent contributions to pelvic anatomy with a elinical introduction. Jour. of Obstet. and Gyn. of Brit. Emp., Jan.

(16) Somers, Geo. B. and Blaisdeld, F. E. 1913 The anatomy and surgical utility of the sacro-uterine ligaments. Jour. Amer. Med. Assoc., vol. 61 , No. 14, Oct. 4 , p. 1247.

(17) Moritz, Manfred 1914 The distribution and significance of the Parametrium. Jour. Obstet. and Gyn., Oct.-Dec., vol. 26, p. 178.

1913 On the nature of the so-called ligaments of Mackenrodt. Journ. Obstet. and Gyn. of the British Empire, March, p. 135.

(18) Fothergill, W. E. and Moritz, M. 1913 The supports of the uterus. The Reviewer, British Medical Journal, Feb. 22.

(19) Cunningham, D. J. 1909 Textbook of Anatomy, 3d Ed.

(20) Morris, H. and McMurrich, J. Playfair 1907 Human Anatomy.

(21) Piersol, Geo. 1907 Human Anatomy.

(22) Gray, Henry 1908 Anatomy, Descriptive and Surgical. 
(23) Emmet, Thos. Aodis 1884 Principles and Practice of Gynecology, 3d Ed.

(24) Schauta, Frisdrich 1896 Lehrbuch der gesammten Gynaekologie, Leipzig und Wien.

(25) Somers, Geo. B. 1912 Utero-vaginal prolapse in elderly woman. Journ. Amer. Med. Assoc., vol. 58, No. 25, June 22, p. 1931.

(26) Keith, Arthur 1902 and 1913 Human Embryology and Morphology.

(27) Paramore, R. H. 1910 Lancet, May, p. 1393. 